http://jmscr.igmpublication.org/home/ ISSN (e)-2347-176x ISSN (p) 2455-0450 crossref DOI: https://dx.doi.org/10.18535/jmscr/v8i4.41

\title{
Clinical and Optical Coherence Tomography Profile of Diabetic Maculopathy in Patients with and without Diabetic Nephropathy
}

\author{
Authors \\ Nethaji Sellaram S, Dalia S \\ Department of Ophthalmology, Govt. TD Medical College, Alappuzha, Kerala - 688005 \\ Corresponding Author \\ Nethaji Sellaram S
}

\begin{abstract}
Purpose: To compare the clinical profile and morphological pattern of Diabetic maculopathy using Optical Coherence Tomography (OCT) in Diabetes mellitus patients with and without Diabetic Nephropathy.

Design: Comparative cross sectional study.

Materials and Methods: 150 patients were enrolled, their clinical profile and diabetic retinopathy status were assessed. Quantitative analysis and morphological pattern of macular edema was compared between the patient having diabetic nephropathy and without nephropathy. Diabetic nephropathy was determined by patient having microalbuminuria, detected by doing spot urine albumin creatinine ratio.

Results: Out of 150 patients $66.7 \%$ patients with Diabetic Nephropathy and $33.3 \%$ without microalbuminuria. 50\% had moderate NPDR, $22.7 \%$ with severe NPDR, $22.7 \%$ with PDR, $4.7 \%$ with mild NPDR changes. Statistical significant difference was seen in better visual acuity (6/6 to 6/18) in patient with (28\%) and without diabetic nephropathy group (46\%). No significant difference was observed in maculopathy status between two groups. Duration of diabetes and hypertension showed no significant difference with the maculopathy severity. OCT pattern in macular edema between two groups showed no significant differences. Mean central foveal thickness in diabetic nephropathy group was $312.62 \pm 85.915$ and without diabetic nephropathy was $289 \pm 73.748$, No significant difference was observed.

Conclusion: Patient without diabetic nephropathy had good vision. Early stage of diabetic nephropathy in the form of microalbuminuria showed no increase in the central foveal thickness. Diabetic nephropathy did not influence the morphological pattern of macular edema.

Keywords: Clinical profile; OCT pattern; Diabetic Maculopathy; Diabetic Nephropathy.
\end{abstract}

\section{Introduction}

In the year 2000, there were around 171 million people with diabetes globally, and by 2030, it is estimated that this number would increase to 366 million. The microvascular complications like retinopathy, nephropathy, neuropathy are linked to the duration of diabetes mellitus, poor glycemic control and systolic hypertension. The magnitude of damage caused by these microvascular complications of diabetes stresses the need for sensitive markers of screening for retinopathy and nephropathy. The sensitive marker for the detection of diabetic nephropathy is to estimate excretion of microalbumin in urine; and for the detection of diabetic retinopathy (DR), to have a fundus evaluation after pupillary dilatation. The 
concordance of microalbuminuria and DR has been well reported in persons with type 1 diabetes; however, for type 2 diabetes, there is paucity of data especially from population-based studies regarding the association of microalbuminuria with DR.

\section{Aim of Study}

To compare the clinical profile and morphological pattern of Diabetic maculopathy using Optical Coherence Tomography (OCT) in Diabetes mellitus patients with and without nephropathy.

\section{Inclusion Criteria}

1. Diabetic maculopathy patients (type I and type with and without nephropathy

2. Patients above 18 years of age

\section{Exclusion Criteria}

1) Treated cases of diabetic retinopathy

2) Nephropathy due to other causes

\section{Materials and Methods}

Study was conducted in retina clinic in department of Ophthalmology outpatient department of government T.D. Medical College and Hospital, Alappuza. 150 patients who satisfied the inclusion criteria were enrolled. Detailed history was elicited and complete ophthalmic examination was done which included recording the best corrected visual acuity, anterior segment examination with slit lamp, fundus examination after dilating with $0.8 \%$ of tropicamide and $5 \%$ phenylephrine using 90 dioptre lens. Severity of retinopathy and maculopathy were graded according to the International Clinical Diabetic Retinopathy and Macular Edema Disease Severity Scale. OCT scanning of macula was done using Carl Zeiss Cirrus HD-OCT model 4000.Using macular cube $512 \times 128$ scan, structural changes, central foveal thickness, type of pattern of macular edema, centre involvement were assessed. Morphological pattern of macular edema were classified into spongiform type, cystoid, with subretinal fluid, taut posterior hyaloid, foveal tractional retinal detachment. Patient's nephropathy status was assessed by doing spot urine albumin creatinine ratio. According to Kidney Disease: Improving Global Outcomes (KDIGO) 2012 guidelines patient having microalbuminuria $<30 \mathrm{mg} / \mathrm{g}$ were grouped as without diabetic nephropathy and patient having $30-300 \mathrm{mg} / \mathrm{g}$ or more were grouped as patients with diabetic nephropathy. Data was analysed using computer software, Statistical Package for Social Sciences (SPSS) version 16. Statistical differences between the two groups were compared with chi square test. For all statistical evaluations, probability of value ( $p$ value), <0.05 was considered significant

\section{Results}

Out of 150 patients enrolled in our study 100 (66.7\%) patients were having microalbuminuria (with Diabetic Nephropathy) and 50 (33.3\%) were not having microalbuminuria (without Diabetic Nephropathy).50\%(75) of patients were having moderate NPDR, 22.7\%(34) were having severe NPDR, 22.7\%(34) were having PDR, and only $4.7 \%(7)$ of the people had mild NPDR changes.84\%(126) were having severe diabetic macular edema, $8.7 \%$ (13) moderate and 7.3\%(11) mild diabetic macular edema

Maximum number patient were in the age group 31 to 70 years $(\sim 90 \%)$. No statistical difference was observed between age and diabetic maculopathy patients, though proportion severe macular edema was seen more in age of 51 to 70 years compared to the younger age group

Table 1: Age and Maculopathy

\begin{tabular}{|c|c|c|c|c|c|}
\hline AGE & \multicolumn{3}{|c|}{ Diabetic macular edema } & Chi square & P value \\
\hline & mild & moderate & severe & 9.308 & 0.157 \\
\hline $18-30$ years & 0 & 0 & 3 & & \\
\hline $31-50$ years & 8 & 6 & 41 & & \\
\hline 51-70 years & 3 & 7 & 69 & & \\
\hline$>70$ years & 0 & 0 & 13 & & \\
\hline
\end{tabular}


There is no statistically significant difference observed between duration of diabetes, hypertension and diabetic maculopathy.

Table 2: Duration of Diabetes, Hypertension and Diabetic Maculopathy

\begin{tabular}{|l|c|c|c|c|c|}
\hline \multirow{2}{*}{$\begin{array}{l}\text { Duration of } \\
\text { diabetes }\end{array}$} & \multicolumn{3}{|c|}{ Diabetic maculopathy } & Chi square & P value \\
\cline { 2 - 4 } & Mild & Moderate & Severe & \multirow{2}{*}{7.136} & 0.308 \\
\hline 1-5 years & 1 & 5 & 21 & & \\
\hline 6-10years & 2 & 4 & 45 & & \\
\hline 11-15years & 4 & 2 & 25 & & \\
\hline$>15$ years & 4 & 2 & 35 & & \\
\hline
\end{tabular}

\begin{tabular}{|l|c|c|c|c|c|}
\hline $\begin{array}{l}\text { Duration of } \\
\text { hypertension }\end{array}$ & \multicolumn{3}{|c|}{ Diabetic maculopathy } & \multirow{2}{*}{$\begin{array}{c}\text { Chi square } \\
\text { value }\end{array}$} & P value \\
\hline & Mild & Moderate & Severe & \multirow{2}{*}{6.475} & 0.372 \\
\cline { 1 - 4 } 1-5 years & 1 & 3 & 17 & & \\
\hline 6-10 years & 0 & 1 & 11 & & \\
\hline 11-15 years & 2 & 0 & 12 & & \\
\hline$>15$ years & 2 & 0 & 11 & & \\
\hline
\end{tabular}

Table 3: Visual Acuity and patients with and without Diabetic Nephropathy

\begin{tabular}{|l|c|c|c|c|c|c|}
\hline \multirow{2}{*}{ Visual acuity } & \multicolumn{4}{|c|}{ Microalbuminuria } & Chi-square & \multirow{2}{*}{ p-value } \\
\cline { 2 - 5 } & \multicolumn{2}{|c|}{ Present } & \multicolumn{2}{c|}{ Absent } & \multirow{2}{*}{7.891} & \multirow{2}{*}{0.048} \\
\cline { 2 - 5 } & $\mathrm{N}$ & $\%$ & $\mathrm{~N}$ & $\%$ & \\
\hline 6/6 to 6/18 & 28 & 28 & 23 & 46 & & \\
\hline 6/24 to 6/60 & 64 & 64 & 20 & 40 & & \\
\hline 5/60 to 3/60 & 4 & 4 & 3 & 6 & & \\
\hline 2/60 to hand movements & 4 & 4 & 4 & 8 & & \\
\hline Total $(\mathrm{N}=150)$ & 100 & 100 & 50 & 100 & & \\
\hline
\end{tabular}

Statistically significant difference in visual acuity was seen between two groups of maculopathy patients. Patient with better VA (6/6 to 6/18) were seen more in patient without diabetic nephropathy group (46\%) compared to patient with nephropathy (28\%). Patient with VA of $6 / 24$ to $6 / 60$ was seen more in patients with diabetic nephropathy. Patient with poor VA (5/60 to hand movements) could not be compared since the number of patient in this group was less.

Table 4: Severity of Diabtic Retinopathy and Maculopathy

\begin{tabular}{|l|c|c|c|c|c|c|}
\hline \multirow{2}{*}{ Retinopathy } & \multicolumn{3}{|c|}{ Maculopathy } & Total & \multirow{2}{*}{$\begin{array}{c}\text { Chi- } \\
\text { square } \\
\text { value }\end{array}$} & P-value \\
\cline { 2 - 5 } & $\begin{array}{c}\text { Mild } \\
\text { DME }\end{array}$ & $\begin{array}{c}\text { Moderate } \\
\text { DME }\end{array}$ & $\begin{array}{c}\text { Severe } \\
\text { DME }\end{array}$ & & \multirow{2}{*}{76.539} & 0.000 \\
\hline Mild NPDR & 6 & 1 & 0 & 7 & \\
\hline Moderate NPDR & 5 & 10 & 60 & 75 & & \\
\hline Severe NPDR & 0 & 2 & 32 & 34 & & \\
\hline PDR & 0 & 0 & 34 & 34 & & \\
\hline Total & 11 & 13 & 126 & 150 & & \\
\hline
\end{tabular}

When the severity of retinopathy increased severity of macular edema also increased. In our study mild NPDR patient did not have severe DME, and PDR patients showed severe DME

Table 5: Diabetic Maculopathy and Diabetic Nephropathy

\begin{tabular}{|l|c|c|c|c|c|c|}
\hline \multirow{2}{*}{$\begin{array}{l}\text { Diabetic macular } \\
\text { edema (DME) }\end{array}$} & \multicolumn{4}{|c|}{ Microalbuminuria } & \multirow{2}{*}{$\begin{array}{c}\text { Chi-square } \\
\text { value }\end{array}$} & \multirow{2}{*}{ p-value } \\
\cline { 2 - 5 } & \multicolumn{2}{|c|}{ Present } & \multicolumn{2}{c|}{ Absent } & \\
\cline { 2 - 5 } & $\mathrm{N}$ & $\%$ & $\mathrm{~N}$ & $\%$ & \multirow{2}{*}{0.156} & \\
\hline Mild DME & 3 & 3 & 2 & 4 & & \\
\hline Moderate DME & 11 & 11 & 1 & 2 & & \\
\hline Severe DME & 86 & 86 & 47 & 94 & & \\
\hline Total & 100 & 100 & 50 & 100 & & \\
\hline
\end{tabular}


Severity of maculopathy in both groups were similar, no significant statistical difference was observed between patient with and without diabetic nephropathy

Table 6: OCT pattern of Diabetic Maculopathy in patient with and without Diabetic Nephropathy

\begin{tabular}{|c|c|c|c|c|c|c|}
\hline \multirow[t]{3}{*}{ OCT PATTERN } & \multicolumn{5}{|c|}{ Microalbuminuria } & \multirow{3}{*}{$\begin{array}{c}\text { P- } \\
\text { Value }\end{array}$} \\
\hline & \multirow{2}{*}{$\begin{array}{c}\text { Total } \\
\mathrm{N}=150\end{array}$} & \multicolumn{2}{|c|}{ Present } & \multicolumn{2}{|c|}{ Absent } & \\
\hline & & $\begin{array}{c}\text { Count } \\
(\mathrm{N}=100)\end{array}$ & $\%$ & $\begin{array}{l}\text { Count } \\
(\mathrm{N}=50)\end{array}$ & $\%$ & \\
\hline Spongiform & 41 & 29 & 29 & 12 & 24 & 0.56 \\
\hline Cystoid & 72 & 44 & 44 & 28 & 56 & 0.13 \\
\hline Subretinal fluid & 18 & 13 & 13 & 5 & 10 & 0.62 \\
\hline Taut posterior hyaloid & 1 & 1 & 1 & 0 & 0 & 0.48 \\
\hline $\begin{array}{l}\text { Fovealtractional retinal } \\
\text { detachment }\end{array}$ & 1 & 1 & 1 & 0 & 0 & 0.48 \\
\hline
\end{tabular}

There is no statistical difference seen in all five pattern of macular edema, between the two groups observed in our study.

Table 7: Central foveal thickness and patient with and without Diabetic nephropathy

\begin{tabular}{|l|c|c|c|l|}
\hline \multirow{2}{*}{ Microalbuminuria } & \multicolumn{3}{|c|}{ Central foveal thickness(CFT) } & \multirow{2}{*}{ P value } \\
\cline { 2 - 4 } & $\mathbf{N}$ & Mean & Std. Deviation & \multirow{2}{*}{0.16} \\
\hline Present & 100 & 312.62 & 85.915 & \\
\hline Absent & 50 & 289.66 & 73.748 & \\
\hline
\end{tabular}

Mean central foveal thickness in patients with DN was $312.62 \pm 85.915$ and patient without DN was $289 \pm$ 73.748. No significant difference was observed between patients with and without nephropathy

Table 8: Centre involving edema in patients with and without Diabetic nephropathy

\begin{tabular}{|c|c|c|c|c|c|c|}
\hline \multirow{3}{*}{$\begin{array}{l}\text { Center involving } \\
\text { edema }\end{array}$} & \multicolumn{4}{|c|}{ Microalbuminuria } & \multirow{2}{*}{$\begin{array}{c}\text { Chi-square } \\
\text { value }\end{array}$} & \multirow[t]{2}{*}{ p-value } \\
\hline & \multicolumn{2}{|c|}{ Present } & \multicolumn{2}{|c|}{ Absent } & & \\
\hline & $\mathrm{N}$ & $\%$ & $\mathrm{~N}$ & $\%$ & 0.103 & 0.749 \\
\hline Present $(n=127)$ & 84 & 84 & 43 & 86 & & \\
\hline Absent $(n=23)$ & 16 & 16 & 7 & 14 & & \\
\hline Total $(n=150)$ & 100 & 100 & 50 & 100 & & \\
\hline
\end{tabular}

No significant difference was seen in centre involving edema between patients with and without diabetic nephropathy.

\section{Discussion}

In our study, age did not show statistically significant correlation in both groups with maculopathy, which was in concurrence with study done by Teiko Yamamoto, Satoshi Iimuro et.al. ${ }^{1}$ However in our study severe form of maculopathy was seen in older group patients 30 to 70 years of age, Which was in concurrence with the study done by Klein et.al., higher rates of maculopathy were found in the presence of nonproliferative diabetic retinopathy in older as compared to younger subjects. ${ }^{2}$ Age-corrected prevalence rates suggest that there is no definite age interaction with duration of disease. ${ }^{3}$ The Diabetes Control and Complications trial reported that the cumulative incidence of severe nonproliferative retinopathy and proliferative retinopathy increased with increasing duration of diabetes ${ }^{4}$ Klein et al. also showed that there was an increase in the prevalence of any type of retinopathy, or proliferative retinopathy, with increasing duration of diabetes. ${ }^{5,6}$ They also reported that the duration of diabetes was a significant risk factor for the development of macular edema in older patients. ${ }^{7}$ However in our study we were not able to show significant 
association of diabetic maculopathy with duration of diabetes mellitus and hypertension, which could be due to smaller sample size of my study.

Duration of hypertension and severity of maculopathy did not show any significant association in my study. To my best knowledge there was no prior report between the correlation of duration of hypertension and diabetic maculopathy. However United Kingdom Prospective Diabetes Study reported that the occurrence of retinopathy was associated with higher systolic blood pressure ${ }^{8}$, and Cahill et al. reported that the incidence of retinopathy was associated with systemic hypertension in patients diagnosed after the age of 70 years ${ }^{9}$. Other study, however, showed that the blood pressure was not significantly correlated with the incidence or progression of retinopathy in the older onset group. ${ }^{10}$

Presence of microalbuminuria doesn't have any significant association with the severity of retinopathy or maculopathy in my study, which is in concurrence with the study by Erasmus et al concluded that concluded that microalbuminuria may not predict retinopathy and occurs independently from either glycaemic control or elevated blood pressure levels ${ }^{11}$.

The Wisconsin Epidemiologic Study of Diabetic Retinopathy group reported that the incidence of macular edema increased significantly with increasing severity of retinopathy. ${ }^{12}$ The data from the present study also show that increase in severity of retinopathy proportionately showed increase in severity of macular edema. Although diabetic macular edema can be seen at any level of diabetic retinopathy, an increasing diabetic retinopathy severity has been associated with an increasing prevalence of diabetic macular edema. $^{13,14}$ About the OCT pattern of macular edema in the study, no single type of pattern of edema were significantly associated with presence or absence of diabetic nephropathy. Even though in our study patient without diabetic nephropathy had more cystoid edema pattern compared with diabetic nephropathy group. In a relation to our study done by Nam Kyun Koo, et al on relationship of morphology of DME and renal dysfunction it was found that subretinal fluid type of edema was seen in high proportion with patient having microalbuminuria. ${ }^{15}$

\section{Conclusion}

Age does not have influence on the severity of diabetic maculopathy, patient without diabetic nephropathy has better quality of vision. Duration of hypertension doesnot have influence over diabetic maculopathy. Early stage of diabetic nephropathy in the form of microalbuminuria does not increase the macular edema, so good control of renal status is necessary in diabetic patients. Diabetic nephropathy doesnot have any unique pattern of macular edema. Retarding the progression of diabetic retinopathy will reduce the severity of diabetic maculopathy.

\section{References}

1. Teiko Yamamoto, Satoshi Iimuro et.al Prevalence and risk factors for diabetic maculopathy, and its relationship to diabetic retinopathy in elderly Japanese patients with type 2 diabetes mellitus. Geriatr Gerontol Int 2012; 12 (Suppl. 1): 134-140g

2. Klein R, Klein BEK, Moss SE, et al. The Wisconsin Epidemiologic Study of Diabetic Retinopathy IV. Diabetic macular edema. Ophthalmology 1984;91:1464-74g

3. Cugati S, Kifley A, Mitchell P, Wang JJ: T emporal trends in the age-specific prevalence of diabetes and diabetic retinopathy in older persons: Populationbased survey findings. Diabetes Res. Clin. Pract. 2006

4. Diabetes Control and Complications trial Research Group. The effect of intensive diabetes treatment on the progression of diabetic retinopathy in insulin-dependent diabetes mellitus. Arch Ophthalmol 1995; 113: $36-51$ 
5. Klein R, Moss SE, Klein BE, Davis MD, DeMets DL. The Wisconsin epidemiological study of diabetic retinopathy. XI. The incidence of macular edema. Ophthalmology 1989; 96: 15011510

6. Klein R, Klein BEK, Moss SE, et al. Th e Wisconsin Epidemiologic Study of Diabetic Retinopthy XIV. Ten-year incidence and progression of diabetic retinopathy. Arch Ophthalmol 2008; 112:1217-28.

7. Klein R, Klein BE, Moss SE, Davis MD, DeMets DL. The Wisconsin Epidemiologic Study of Diabetic Retinopathy, II. Prevalence and risk of diabetic retinopathy when age at diagnosis is less than 30 years. Arch Ophthalmol1984; 102: 520-526.

8. Stratton IM, Kohner EM, Aldington SJ et al. UKPDS 50: risk factors for incidence and progression of retinopathy in type II diabetes over 6 years from diagnosis. Diabetologia2001; 44: 156

9. Cahill M, Halley A, Codd $M$ et al. Prevalence of diabetic retinopathy in patients with diabetes mellitus diagnosed after the age of 70 years. Br J Ophthalmol 1997; 81: 218-222

10. Klein R, Klein BE, Moss SE, Davis MD, DeMets DL. Is blood pressure a predictor of the incidence or progression of diabetic retinopathy? Arch Intern Med 1989; 149: 2427- 2432

11. Erasmus RT, Oyeyinka G, Arije A: Microalbuminuria in non-insulindependent (type 2) Nigerian diabetics: relation to glycaemic control, blood pressure and retinopathy. Postgrad Med J 1992, 68:638-42.
12. Klein R, Klein BEK, Moss SE, et al. Th e Wisconsin Epidemiologic Study of Diabetic Retinopthy XIV. Ten-year incidence and progression of diabetic retinopathy. Arch Ophthalmol 2008; 112:1217-28

13. Lattanzio R, Brancato R, Pierro L, Bandello F, Iaccheri B, Fiore T, Maestranzi G. Macular thickness measured by optical coherence tomography (OCT) in diabetic patients. Eur J Ophthalmol. 2002;12:482-7.

14. Browning DJ, Fraser CM, Clark S. The relationship of macular thickness to clinically graded diabetic retinopathy severity in eyes without clinically detected diabetic macular edema. Ophthalmology. 2007;115:533-9.

15. Nam Kyun Koo, Hyun Cheol Jin, Kwang Soo Kim, Yu Cheol Kim Relationship between the Morphology of Diabetic Macular Edema and Renal Dysfunction in Diabetes. Korean journal of ophthamol. 2013;27(2): ISSN: 1011-8942 . 98-102. 